\title{
El Generalísimo: configuración, prácticas políticas y representación del poder supremo (México, 1810-1822)
}

\author{
por \\ Moisés Guzmán Pérez ${ }^{1}$ \\ Universidad Michoacana de San Nicolás de Hidalgo
}

Este artículo tiene por objeto analizar la lógica politica del empleo de Generalísimo en México durante el proceso de emancipación. Estudia su trayectoria militar, las circunstancias en que accedieron al cargo y las actividades que desarrollaron al frente de sus ejércitos entre 1810 y 1822. El tema resulta atractivo y revelador, puesto que permite entender cómo se comenzó a perfilar la figura del caudillo y la manera en la que ejerció el poder supremo en el siglo XIX. La información proviene, principalmente, de archivos y bibliotecas mexicanos y españoles, y de la consulta de una bibliografía de una bibliografia especializada sobre la Independencia de México.

PALABRAS Clave: Generalísimo; prácticas políticas; poder supremo; guerra e independencia; México.

Cómo Citar este artículo / Citation: Guzmán Pérez, Moisés, "El Generalísimo: configuración, prácticas políticas y representación del poder supremo (México, 1810-1822)", Revista de Indias, LXXIX/275 (Madrid, 2019): 165-196. https://doi.org/10.3989/revindias.2019.006.

En la actualidad la investidura de Presidente de la República conlleva una altísima responsabilidad y una diferenciada representación dentro y fuera de México. Además de recaer en él la titularidad del Poder Ejecutivo y de fungir como jefe de Estado y jefe de gobierno, es el Comandante Supremo de las Fuerzas Armadas Mexicanas, función esta última que los primeros magistrados de la nación comenzaron a ejercer poco después de consumada la independencia con la creación de la Secretaría de Guerra y Marina. Hoy día, tal distinción viene a ser la de mayor jerarquía en el escalafón militar, seguida

1 moisesguzmanp@hotmail.com, ORCID iD: https://orcid.org/0000-0001-7470-2484. de uso y distribución Creative Commons Reconocimiento 4.0 Internacional (CC BY 4.0). 
del Secretario de la Defensa, los Generales de la Fuerza Aérea, los Generales del Ejército, los Jefes, Oficiales y Tropa.

Sin embargo, tales nombramientos y jerarquías no siempre fueron así, unos desaparecieron y otros se fueron transformando a lo largo del tiempo, conforme la realidad política nacional o internacional lo exigía. Hubo una época en que el responsable de las fuerzas de mar y tierra - las del aire no existíanfue conocido con el nombre de Generalísimo, un título honorífico heredado de la historia cultural de España y que en el reino de la Nueva España - el más floreciente de la monarquía católica-, estuvo por encima del de teniente general de los ejércitos y capitán general que tenían los virreyes en aquel tiempo ${ }^{2}$.

De acuerdo con Borreguero Beltrán, se nombra Generalísimo al «jefe que manda el estado militar en paz y en guerra, con autoridad sobre todos los generales del ejército ${ }^{3}$. Aunque no de manera exclusiva, el concepto ha estado asociado a las dictaduras militares de los siglos XIX y XX, tanto en Europa como en América Latina, con personajes tan representativos como Pedro Quinto en Portugal, Francisco Franco en España, Francisco de Miranda en Venezuela o Rafael Leónidas Trujillo en República Dominicana, por citar sólo algunos que detentaron ese título.

Con ciertas particularidades, propias de su época y circunstancia histórica, se puede observar en ellas - las dictaduras - el ejercicio unipersonal de un poder ilimitado, encarnado en individuos que responden a los valores y creencias de su tiempo, vinculados estrechamente con la fuerza y con la violencia, que buscan legitimidad apelando al populismo o al nacionalismo para alcanzar una fidelidad más permanente y que para lograrlo echan mano de mecanismos psíquicos y actitudes públicas que recuerdan a las antiguas monarquías ${ }^{4}$.

En estricto sentido del término, las dictaduras son situaciones políticas caracterizadas por la defensa que se hace de un poder constituido legítimamente, amenazado por un peligro excepcional y en las cuales un hombre o un grupo de hombres, suspenden transitoriamente la vigencia de dicho orden para derrotar a los enemigos del mismo y restaurarlo inmediatamente, una vez alejado el peligro 5 .

2 Bandos de indulto dados por Venegas, México, 4 de noviembre de 1810, (consultado el 21-IX-2016), http://www.biblioteca.tv/artman2/publish/1810_115/El_virrey_publica_los_ bandos_de_indulto_dictados_por_el_se_or_Calleja_en_San_Juan_del_R_o_ampliando_sus_ determinaciones_printer.shtml

3 Borreguero, 2000: 157.

4 González Casanova, 1981: 7-13.

5 Ibidem: 12. 
Sin embargo, para el caso de América Latina no resulta sencillo enmarcar a los distintos países en este tipo de regímenes. Como explica Arreola, los movimientos armados de cariz revolucionario, el fomento de héroes míticos convertidos en caudillos, el llamado continuo al orden constitucional, la cuestión racial y la estratificación social propias de cada región, así como la política intervencionista de los Estados Unidos en varios de esos países, impiden su «encuadramiento político exacto», acercándose más a lo que algunos autores consideran semidictaduras ${ }^{6}$.

El presente estudio tiene por objeto analizar la lógica política de este importante título militar en México durante el proceso de emancipación, cuando aún no existen dictaduras formales y el orden constitucional del futuro Estado-nación apenas está en gestación. Se interesa por rastrear sus antecedentes en la Península y las atribuciones de que estuvieron investidas las personas que llegaron a representar dicho empleo. Así mismo, se propone analizar la trayectoria militar previa y las circunstancias en que fueron designados los Generalísimos entre 1810 y 1821, así como las diversas actividades que desarrollaron cuando estuvieron al frente de sus respectivos ejércitos. Todo ello nos ayudará a entender cómo se empezó a perfilar la figura del caudillo y la manera en que ejerció el poder supremo.

Nuestra perspectiva de análisis parte de los presupuestos teórico-metodológicos de la historia política y la historia militar con un enfoque cultural. La primera, centrada más en actores concretos, en hombres de carne y hueso, con ideas e intereses diversos en torno al poder el cual ejercen desde distintos espacios simbólicos, en la manera de relacionarse y en los mecanismos - legales o no- de los que echan mano para acceder a él. De esta manera se entreteje un complejo entramado, a veces de subordinación, a veces de conflicto que deja al descubierto una singular convivencia entre gobernantes y gobernados en una cultura política determinada. Y la segunda, interesada no sólo en caudillos, batallas y sitios memorables, sino también en la organización, estructura y funcionamiento de las fuerzas armadas, en sus economías de guerra y formas de financiamiento, en los planes estratégicos y las tácticas de combate, en la innovación tecnológica y las técnicas de fortificación, en la cultura libresca y la cultura de la guerra y para el caso que nos interesa, en las figuras castrenses que emergen en épocas de conflicto armado o de crisis política, en sus representaciones simbólicas, en sus atribuciones omnímodas, por no decir dictatoriales; en la legislación que le va dando forma y sustento legal y en las acciones militares que justifican y a la vez legitiman su razón de ser.

\footnotetext{
6 Arreola, 2008: 179-183.
} 
Para su confección, hemos acudido a fuentes documentales de archivos de México y España, fundamentalmente, así como a una bibliografía especializada y selecta que albergan distintas instituciones académicas de ambos países, la cual nos permitió trazar de forma puntual el perfil político-militar de los cuatro Generalísimos que ha habido en la historia de México, las circunstancias en que se hicieron del poder y la manera en que lo ejercieron.

\section{EL ANTECEDENTE ESPAÑOL}

Durante el reinado de Carlos IV (1784-1808) en que la corona española enfrentó distintos conflictos bélicos con países como Inglaterra, Francia y el mismo Portugal, se diseñaron dos esquemas de articulación de los órganos superiores de defensa para dirigir la guerra, los mismos que en distinto momento fueron encabezados por Manuel Godoy, hombre de confianza del soberano. El primero de dichos esquemas se puede observar en la guerra que sostuvo España contra Francia en la famosa campaña del Rosellón (1795-1796), al final de la cual Godoy alcanzaría el pomposo título de «Príncipe de la Paz», luego de la firma del Tratado de Basilea por los ministros plenipotenciarios de ambas naciones ${ }^{7}$. Para delinear su plan de ataque, el monarca se apoyaba en un Consejo de Guerra y una Junta de Generales; en ellos tenían voz, respectivamente, ministros de condición civil y generales con mando o sin él ${ }^{8}$.

El segundo esquema contempló la creación de un Generalísimo, cargo que recayó por primera vez en la persona de Godoy en 1801 durante la llamada «guerra de las naranjas», conflicto que enfrentó a España con Portugal durante dieciocho días y que fue motivada por cuestiones geoestratégicas, militares y territoriales promovida por Napoleón Bonaparte y ejecutada por Carlos IV contra el reino de Portugal, que tenía por aliado a Inglaterra, enemiga de Francia. Escribe Godoy en sus Memorias que «Carlos IV, con el fin de separar cualquier especie de rivalidad, cualquier idea de preeminencia por parte de los generales extranjeros», le confirió el título y el rango de Generalísimo de mar y tierra, teniendo como una de sus principales funciones la elaboración de reglamentos y ordenanzas militares de España ${ }^{9}$. Desde entonces desapareció el Consejo de Guerra para ser sustituido por la reunión de los secretarios de Estado, Hacienda y Guerra, y a su vez, la Junta de Generales se convirtió

7 Godoy, 1836, tomo I: 291-299. Sobre el título de Príncipe de la Paz, véase la nota de la página 320 .

8 Alonso Baquer, 1972: 151.

9 Godoy, 1836, tomo III: 98, 299. 
por primera vez en la historia en «un Estado Mayor de Operaciones con propósitos de permanencia», en palabras de Alonso Baquer ${ }^{10}$.

El cargo de Generalísimo suponía un grado superior al mariscal de campo y al de almirante, según se podía apreciar en la cédula real de 13 de enero de 1807 expedida por Carlos IV, a través de la cual el monarca español tuvo a bien declarar las facultades, tratamiento y prerrogativas que en adelante gozaría su protegido, como Generalísimo y Gran Almirante a la vez ${ }^{11}$. Esa sería la figura que prevaleció en varios países de Hispanoamérica, particularmente en la Nueva España, al momento de la crisis política de la monarquía en 1808. $\mathrm{Y}$ es que, como escribió el propio Godoy en sus Memorias, fue durante los dos últimos años de su carrera política (1806-1808) como Generalísimo y Gran Almirante, que el vulgo creyó ver el apogeo de su poderío, las riendas del Estado en sus manos, lo cual estaba muy lejos de la realidad ${ }^{12}$.

Después de la destitución de Godoy y su exilio en Francia, no hubo más Generalísimos durante el gobierno absolutista de Fernando VII ni en los demás que le sucedieron. Hasta donde se sabe, el título no volvió a usarse en la Península sino hasta la tercera década del siglo XX por el militar nacido en El Ferrol, Francisco Franco Bahamonde, impulsor del golpe de Estado de 1936 contra el gobierno democrático de la Segunda República' ${ }^{13}$.

En cuanto a la revolución de 1810 en Nueva España, la dirigencia insurgente contó entre sus filas a decenas de jefes y caudillos regionales con mando de tropa de calidad y condición social muy diversa. Figuraban entre ellos clérigos, militares, abogados, hacendados, rancheros, mineros, comerciantes y gobernadores de los pueblos de indios, entre otros, quienes no tardaron en obtener de los principales jefes un título militar. Todos llegaron a ostentar los grados y empleos señalados en las Ordenanzas de Carlos III, vigentes desde mediados del siglo XVIII, pero sólo tres de ellos — dos curas y un capitán — llegaron a fungir como Generalísimos, título que, como indicamos, no existía en las Ordenanzas del ejército. El movimiento armado que inició en Iguala el 24 de febrero de 1821 y concluyó el 27 de septiembre siguiente no tuvo un caudillo con ese nombre, el que se acuñó fue el de Primer Jefe del Ejército Imperial de las Tres Garantías representado por Agustín de Iturbide. Sin embargo, esos siete meses bastaron

10 Alonso Baquer, 1972: 151.

11 https://books.google.com.mx/books?id=Zxgm15f9QCwC\&pg=PA1\&lpg=PA1\&dq= general $\%$ C3\%ADsimo\&source $=$ bl\&ots $=$ oodDqQs $75 \mathrm{~m} \& \operatorname{sig}=1 \mathrm{USRC} 4 \mathrm{WJ} 3 \mathrm{~S} 7 \mathrm{XdNegxZ}$ GyacLwSts\&hl=es-419\&sa=X\&ved=0ahUKEwjWoZeXuvTMAhUOQFIKHegQCSIQ6AE IaDAQ\#v=onepage $\& \mathrm{q}=$ general $\% \mathrm{C} 3 \% \mathrm{ADsimo} \& \mathrm{f}=$ false

12 Godoy, 1836, tomo III: 223.

13 González Casanova, 1981: 297-365. 
para que el «varón de Dios» — como lo llamó Rafael Heliodoro Valle—, consolidara su fama y ya como presidente de la Regencia, la Soberana Junta Provisional Gubernativa lo nombrara Generalísimo y Almirante en un contexto político muy distinto, diferente de aquel que caracterizó a la insurgencia.

\section{HidAlgo: LA ACCIDENTADA ELECCIÓN DEL PRIMER GENERALÍSIMO}

A pesar del discurso retórico de la dirigencia insurgente en contra del «mal gobierno», lo cierto es que, ante la imposibilidad de inventar algo nuevo, los principales caudillos del movimiento mantuvieron vigentes por un tiempo ciertas figuras de autoridad creadas por los Borbones, así como algunas de las instituciones políticas emanadas de aquel régimen. Entre las primeras podemos señalar, por ejemplo, a los subdelegados, los intendentes y el mismo empleo de Generalísimo; entre las segundas figuran los ayuntamientos, las intendencias y la Audiencia ${ }^{14}$.

El cargo de Generalísimo con el que en su momento fueron investidos Miguel Hidalgo e Ignacio Allende, no estuvieron exentos de intrigas, confrontaciones y deseos de mando mal encausados. Como es sabido, Hidalgo inició la insurrección armada en Dolores la madrugada del 16 de septiembre de 1810 y a los pocos días se vio al frente de una muchedumbre con un título militar que él mismo se otorgó, semejante al que usaba el virrey Francisco Xavier Venegas. Desde entonces el cura comenzó a firmar sus bandos, decretos y manifiestos como «capitán general de América», eliminando en lo sucesivo toda alusión a la Nueva España y sustituyendo el vocablo «real» por «nacional» en muchos de sus escritos ${ }^{15}$.

Quizá fue aquello lo que desde un inicio incomodó a Allende, pues no concebía que un cura de pueblo que no sabía nada de táctica y planes de ataque, dirigiera la revolución. El distanciamiento entre ellos comenzó en Celaya, pero se agravó en Valladolid desde que Allende se dio cuenta que Fernando VII, el rey «deseado» por quien una inmensa mayoría clamaba, había dejado de ser el motivo de la rebelión, pues no aparecía más en los bandos y proclamas de los insurrectos ${ }^{16}$. Sin embargo, poco podía hacer en tanto Hidalgo figurara como principal caudillo del movimiento.

14 Ortiz Escamilla, 2014: 35-37, 115, 118, 121. Herrejón Peredo, 2011: 433.

15 Herrejón Peredo, 2011: 320-321, 329-330, 436. Donación, Valladolid, 18 de octubre de 1810, Archivo General de Notarías de Morelia, Morelia, México (AGN-Mor), Protocolos de José Gerónimo Marocho, vol. 227, años 1809-1810, fs. 567-567v.

16 Guzmán Pérez, 2011: 152. Herrejón Peredo, 2011: 352-353. 
Luego que el contingente insurgente salió de Valladolid el 19 de octubre de 1810 con dirección a Acámbaro, Allende comenzó a platicar con varios militares sobre la falta de capacidad del cura para organizar y disciplinar todas sus fuerzas. Le cuestionaba su falta de firmeza para castigar a los que se dedicaban al saqueo y reprobó los asesinatos cometidos por la indiada en la alhóndiga de Granaditas. Por todo ello, al llegar a aquella villa, el capitán san miguelense promovió una junta de todos los oficiales con el objeto de «deponer a Hidalgo de todo mando», logrando atraerse la voluntad de los jefes de la Plana Mayor. Mariano Jiménez que estaba presente, dijo que cuando Hidalgo escuchó la propuesta «se enfureció terriblemente, con lo que intimados los vocales, en lugar de deponerlo lo proclamaron Generalísimo de capitán general que era» ${ }^{17}$, y así fue como el 22 de octubre de 1810 en Acámbaro, el cura se hizo con aquel empleo.

Diego García Conde, oficial realista que había sido aprehendido por los rebeldes junto con Diego Rul y el intendente Manuel Merino en el camino cercano a Acámbaro, informó meses después, luego de quedar libre, que «los nuevamente ascendidos se pusieron sus uniformes y divisas, siendo el de Hidalgo un vestido azul con collarín, vuelta y solapa encarnada con un bordado de labor muy menuda de plata y oro, un tahalí negro, también bordado y todos los cabos dorados, con una imagen grande de nuestra señora de Guadalupe de oro colgada en el pecho» ${ }^{18}$.

Ya como Generalísimo, Hidalgo ordenó la fabricación de cañones, armas blancas y municiones para dotar a sus fuerzas y a estilo de Ordenanza expidió nombramientos a varios oficiales. Allende fue designado capitán general; Mariano Balleza, Mariano Jiménez, Joaquín Arias y Juan Aldama recibieron el título de tenientes generales, mientras que Marino Abasolo, Joaquín Ocón y los dos Ignacio Martínez, ascendieron a mariscales de campo ${ }^{19}$. También expidió oficio de capitán a Pedro José Beltrán Mesa Coronel, comisionado para insurreccionar el Real del Rosario, en Sinaloa ${ }^{20}$. En su declaración ante el

17 Proceso de Mariano Jiménez, Chihuahua, 22 de mayo de 1811, en Montejano y Aguiñaga, 1981: 13. Herrejón Peredo, 2011: 360.

18 García Conde a Venegas, México, 8 de diciembre de 1810, en Hernández y Dávalos, 1985, tomo II, n. ${ }^{\circ} 156: 268$. El uso del vestuario con ciertos colores e insignias era fundamental en las sociedades corporativas de Antiguo régimen donde el protocolo, el ceremonial y la etiqueta decían mucho de las diferencias y al mismo tiempo de sus jerarquías. El sector castrense no fue la excepción, se puede ver en sus uniformes, en sus divisas y condecoraciones, que correspondían a un determinado grado militar y a sus méritos en campaña.

19 Ibidem: 271.

20 Nombramiento expedido por Hidalgo, Acámbaro, 23 de octubre de 1810, en Lemoine Villicaña, 1965: 157-158. 
fiscal Hidalgo precisó que esta prerrogativa no era exclusiva de él, «pues también el capitán general y los demás generales que se hallaban distantes del centro del gobierno y el cuerpo de la oficialidad, hacían y promovían lo que se le antojaba» ${ }^{21}$, lo cual significa que el cura no llegó a tener el mando efectivo de todos los jefes rebeldes que participaban en el movimiento, situación que probablemente también motivó el enojo de Allende.

Lo que sí logró Hidalgo fue que la mayoría de sus fuerzas usaran como escudo en sus banderas la imagen del águila o de la virgen de Guadalupe como principal emblema de lucha, tal como se señala en infinidad de partes militares remitidos por los oficiales realistas, así como en diversos testimonios insurgentes de la época. Por ejemplo, los cabecillas Manuel Vega y Francisco Hernández, «comandantes del ejército americano del Generalísimo don Miguel Hidalgo» que se levantaron en armas en el pueblo de Iguala, en el actual estado de Guerrero, tuvieron el encargo de incursionar por toda la Costa Sur de la intendencia de México enarbolando una bandera con la imagen mariana ${ }^{22}$.

Las facultades del Generalísimo no se circunscribían al ámbito de lo estrictamente militar. Tal designación le permitía tomar determinaciones «en todos los ramos», es decir, en materia de justicia, hacienda, guerra y policía, las cuatro causas consignadas en la Real Ordenanza de Intendentes de 1786, sin olvidar su intervención en asuntos tocantes al patronato, a través del otorgamiento de prebendas y dotación de beneficios eclesiásticos ${ }^{23}$. Respecto a esto último, así lo había hecho en Valladolid en octubre de 1810 cuando sólo era capitán general: esa vez quitó a dos clérigos del cabildo sus prebendas, los mandó encarcelar y él mismo las concedió a otros curas de su confianza ${ }^{24}$. De igual modo, siendo ya Generalísimo, el 5 de diciembre en Guadalajara preparó el nombramiento de «medio racionero» de la catedral de aquella diócesis a favor del bachiller José Manuel Tamayo y Mastranzo, el cual, según Herrejón, no llegó a tener efecto porque el documento carecía de firma ${ }^{25}$.

${ }^{21}$ Declaración de Hidalgo, Chihuahua, 6-7 de mayo de 1811, en Hernández y Dávalos, 1985, tomo I, n. ${ }^{\circ}$ 2: 10.

${ }^{22}$ Certificación y fe, José Ignacio Rosillo, Real de Minas de Taxco, 23 de noviembre de 1810, Archivo General de la Nación, Ciudad de México (AGN), Operaciones de Guerra, vol. 712, f. 186. Andrade a Venegas, Tepecuacuilco, 6 de diciembre de 1810, AGN, Operaciones de Guerra, vol. 712, f. 218. Bernardo Tadeo de la Guerra a Andrade, Tixtla, 21 de noviembre de 1810, AGN, Operaciones de Guerra, vol. 712, f. 181r.

${ }^{23}$ Declaración de Hidalgo, Chihuahua, 6-7 de mayo de 1811, en Hernández y Dávalos, 1985, tomo I, n. ${ }^{\circ}$ 2: 13.

24 Guzmán Pérez, 2011: 142-143.

25 Herrejón Peredo, 2007: 37, 53. 
Con excepción de los manifiestos que Hidalgo hizo públicos en Valladolid y la villa de Zamora en noviembre de 1810, en los que propuso la instalación de un Congreso de representantes de las principales ciudades, villas y lugares del país «que dicte leyes...», e interpeló a los criollos americanos que militaban en las filas realistas exhortándolos a apoyar la insurgencia ${ }^{26}$, la actividad más fecunda fue la que realizó durante su residencia en Guadalajara, capital de la Nueva Galicia, donde según Ignacio Aldama «le empezaron a dar el tratamiento de Alteza Serenísima» ${ }^{27}$.

Ya solo, ya acompañado, desde aquel lugar otorgó decenas de nombramientos militares, varios administrativos y uno plenipotenciario al guatemalteco Pascasio Ortiz de Letona (13-XII-1810). Además, publicó un bando prohibiendo en lo sucesivo que se tomen caballos y forrajes sin expresa orden del juez de la demarcación (1-XII-1810), circuló otro sobre el arriendo de tierras pertenecientes a los pueblos de indios (5-XII-1810) y otro más contra la esclavitud, las gabelas y el papel sellado (6-XII-1810). De igual modo, se reservó su opinión sobre el destino de los dineros incautados a los europeos, condescendió con el asesinato de peninsulares y dirigió la batalla decisiva contra los realistas en Puente de Calderón. No está de más señalar que antes de aquel enfrentamiento, Hidalgo difundió una proclama justificando el derecho natural que tenían los americanos al autogobierno ${ }^{28}$.

Más allá de las disposiciones que en materia política, militar, económica, social y diplomática dictó Hidalgo como Generalísimo, lo más significativo fue la manera autocrática como se conducía. Herrejón señala que la Audiencia Nacional creada en Guadalajara tuvo una actuación poco significativa, porque Hidalgo «asumió poder soberano, lo ejerció a menudo autocráticamente y sólo a discreción delegaba» ${ }^{29}$.

Además del insurgente Ignacio Allende, que en varias ocasiones cuestionó las medidas militares tomadas por Hidalgo, el partidario del realismo que más atacó la figura del Generalísimo fue el doctor fray Ramón Casaús, originario de Jaca, en España. En sus dieciséis cartas que por entregas publicó en el Diario de México a partir de noviembre de 1810 y que luego reunió en un folleto con el título de El Anti-Hidalgo, decía que tan luego como se hizo con aquel título se convirtió en "pacha máximo de la renovación americana». Agregó que todo lo que hacía aquel «Generalísimo capataz de salteadores y

26 Herrejón Peredo, 2011: 405-424.

27 Declaración de Juan Aldama, Chihuahua, 21 de mayo de 1811, en García, 1985, tomo VI: 540. Rivera y San Román, 2010: 31.

28 Herrejón Peredo, 2007: 29-40, 48-50; 2011: 429.

29 Herrejón Peredo, 2007: 35; 2011: 404. 
asesinos» eran «actos de capricho absoluto y despótico», que era un monstruo que por sus «disposiciones generalicias aniquilaría la religión verdadera», que usaba «la estola sobre el uniforme de Generalísimo» y que sus ilusiones de entronizarse se perdieron luego de la derrota que sufrió la insurgencia el 17 de enero de 1811 en la batalla de Calderón ${ }^{30}$.

\section{El Generalísimo Allende: un Cargo fugaz}

Si bien la designación de Hidalgo como Generalísimo se gestó en un clima de oposición y protesta por parte de un número importante de jefes y oficiales, algunos de los cuales al final decidieron proclamarlo como tal en la villa de Acámbaro, la manera como Allende llegó a ocupar el cargo fue a través de un acto de fuerza, uno de tantos que se dieron en México en el transcurso del siglo XIX.

La carrera militar de Allende comenzó en 1795 a los 26 años de edad, cuando se le dio de manera provisional el título de teniente de la tercera compañía del Regimiento de Dragones de la Reina, mismo que le fue confirmado por despacho real el 19 de febrero de 1796. En 1801 recibió el nombramiento de teniente de granaderos por parte del virrey Félix Berenguer y Marquina y luego de varios años, por muerte de Juan José González, en diciembre de 1808 solicitó y le fue concedido el título de capitán del mismo Regimiento $^{31}$. Ese fue el empleo que detentaba al inicio de la insurrección, hasta octubre de 1810 en que ocurrió la promoción de los militares en Acámbaro, de cuyas resultas recibió del Generalísimo Hidalgo el título de capitán general; con éste se mantuvo hasta finales de enero de 1811 en que decidió hacerse con el mando absoluto del movimiento.

En efecto, luego del desastre que sufrieron las fuerzas insurgentes en Puente de Calderón, cerca de Guadalajara, los caudillos huyeron hacia el norte buscando ayuda de los Estados Unidos. En el trayecto Hidalgo fue alcanzado por Allende y sus oficiales en la hacienda de Pabellón, una finca ubicada entre Guadalajara y la villa de Aguascalientes. Fue en ese lugar donde Allende, «se aprovechó del disgusto de la oficialidad del ejército con Hidalgo, por sus malas disposiciones, para que en una junta se le depusiese del mando, lo que se verificó...por acuerdo de los mismos oficiales» ${ }^{32}$. Hidalgo

30 Casaús, 1988: 71, 78, 91, 161, 180, 181, 183-184, 190, 196.

31 Rivas de la Chica, 2013: 95, 99-100.

32 Causa instruida contra el Generalísimo D. Ignacio de Allende, Chihuahua, 10 de mayo29 de junio de 1811, en García, 1985, tomo VI: 32. Herrejón Peredo, 2011: 494-495. 
confirmó esto en su proceso, al señalar que el propio Allende, respaldado por el teniente general Joaquín Arias, José Miguel Arroyo y otro de su facción apellidado Casas, le amenazaron «de que se le quitaría la vida si no renunciaba el mando en Allende, lo que hubo de hacer y se hizo verbalmente y sin ninguna otra formalidad» ${ }^{33}$.

Allende quedó pues como Generalísimo a partir del 25 de enero de 1811 sin que la tropa se enterara del despojo. En apariencia Allende ejercería el mando militar mientras que Hidalgo conservó el político. Al día siguiente, Allende le escribió una carta a José María Tejeda informándole haber recibido los 23 mil 600 pesos de las haciendas que este último administraba, haciéndole saber además la noticia «de haber renunciado Hidalgo, el 25 de enero, al mando de la comandancia de armas y recaído por votos universales en dicho Allende» ${ }^{34}$.

Por otro lado, las investiduras que portaba Allende de capitán general fueron sustituidas por las de Generalísimo «y tomó el gobierno y facultades que tenía su antecesor» ${ }^{35}$. Sin embargo, muy pocas disposiciones pudo dictar con ese carácter. Sólo se cuenta la comisión que dió a Mariano Ximénez «para levantar ejército en la provincia de San Luis Potosí y conquistar las Provincias Internas» ${ }^{36}$, y la junta de generales a que convocó el 16 de marzo de aquel año en la villa de Saltillo, Coahuila. En dicha reunión se determinaron tres cosas: primeramente, que Hidalgo ratificara su renuncia que había hecho del título de Generalísimo, sobre lo cual no hubo mayor discusión. En seguida, se dispuso que los principales jefes continuaran su marcha hacia el norte y que la otra parte de sus fuerzas regresaran al centro del virreinato para reactivar la insurrección, quedando éstas bajo el mando del licenciado Ignacio Rayón que allí mismo fue nombrado general ${ }^{37}$. Finalmente, Allende expidió el nombramiento de vicario general castrense de los ejércitos insurgentes al religioso carmelita fray Gregorio de la Concepción, personaje que se había unido al contingente a su paso por Agua Nueva. Ese día hubo toros y festejos en Saltillo «en honor de los generales a quienes la traición acechaba ya» ${ }^{38}$.

33 Declaración de Hidalgo, Chihuahua, 6-7 de mayo de 1811, en Hernández y Dávalos, 1985, tomo I, n. ${ }^{\circ}$ 2: 8 .

34 Herrejón Peredo, 2007: 51-52.

35 Causa instruida contra el Generalísimo D. Ignacio de Allende, Chihuahua, 10 de mayo29 de junio de 1811, en García, 1985, tomo VI: 50.

36 Declaración de Ignacio Aldama, Chihuahua, 21 de mayo de 1811, en García, 1985, tomo VI: 535. Rivera y San Román, 2010: 31.

37 Erróneamente, Búlnes le da título de Generalísimo. Búlnes, 1910: 158-159.

38 Villaseñor y Villaseñor, 1963, tomo I: 86. 
Poco antes de que los jefes del movimiento acordaran separarse, Allende le dio una orden reservada al general Rayón indicándole que si el comandante Rafael Iriarte - alias Cabo Laiton-, se le presentara en su campamento con cualquier pretexto, procediera a fusilarlo de inmediato, pues era prueba de que preparaba una nueva porfía en contra de ellos ${ }^{39}$. Es por eso que Rayón no tuvo ningún miramiento al momento de aprenderlo y ordenar su ejecución.

Por la correspondencia que hubo entre Allende y Rayón, se sabe que este último le reconoció a aquel su título de «Generalísimo de los ejércitos americanos» con la distincion de Alteza Serenísima, y que poco pudo hacer como general para rearmar a los revolucionarios que quedaron en Saltillo. Más de un centenar de fusiles eran inservibles, los cañones no podían usarlos por falta de cureñas, buena parte del material bélico necesitaba reparación y faltaba dinero para cubrir los gastos que exigía el estado de guerra ${ }^{40}$.

Por otra parte, una situación inesperada ocurrió en Saltillo. Poco después de la derrota de Calderón, debido a la «malignidad o la imprudencia» de algunas personas, se esparció el rumor de que el Generalísmo Hidalgo rompería todos los lazos que mantenían unida a la Nueva España con su metrópoli «declarándose por artículo primordial su total independencia del trono de los Borbones». Dice Rayón que

... apenas circuló vaga esta voz, desertó de nuestras banderas considerable número de soldados, repitiéndose en los días, siguiendo la deserción y notándose generalmente un disgusto, sobremanera peligroso. Aún pasó adelante el estrago y fueron terribles sus consecuencias. Los desertores engrosaron el partido débil de los enemigos en aquel rumbo y cundió la desconfianza y el daño, hasta cometer el enorme atentado de aprisionar en Béjar al benemérito Aldama y en Acatita de Baján a los primeros jefes... ${ }^{41}$.

Como es sabido, Allende y sus hombres fueron traicionados por Ignacio Elizondo y sorprendidos en las norias de Baján, en la antigua intendencia de la Nueva Vizcaya (actual Coahuila). De ahí fue trasladado al presidio de Chihuahua donde luego del proceso a que fue sometido, murió fusilado el 26 de junio de 1811 terminando así sus días el segundo Generalísimo de la historia de México. Un mes después correría la misma suerte el cura Hidalgo, el primero que gozó de tal distinción.

39 Ibidem: 91.

40 Rayón a Allende, Saltillo, 16 de marzo de 1811, en García, 1985, tomo VI: 89-90.

41 Rayón al Congreso, Chilpancingo, mediados de noviembre de 1813, en Lemoine Villicaña, 1963: 547-548. Ortiz Escamilla, 2014: 228. 


\section{LA DESIGNACIÓN DEL GENERALÍ́SIMO CONFORME A LA LEY}

Como se ha visto, durante la primera etapa de la lucha armada (18101811), bastaba con el voto unánime y/o mayoritario de los capitanes generales y de sus oficiales subordinados, para elegir y «proclamar» al Generalísimo, o bien, para que con el respaldo de ellos se impusiera algún otro. Nada se había normado o reglamentado hasta entonces por la dirigencia insurgente, fueron las propias circunstancias de la guerra las que hicieron que los hombres conocedores de la ley y del derecho se ocuparan de este asunto.

Fue con el licenciado Rayón en abril de 1812 cuando por primera vez se trató de legislar sobre la designación, funciones y prerrogativas que debería ejercer la persona que fuere elegido Generalísimo. En sus conocidos Elementos Constitucionales que remitió a José María Morelos desde Zinacantepec, propuso que sólo en caso de guerra los oficiales de brigadier arriba y los consejeros de guerra al Supremo Congreso Nacional, estuvieran facultados para proponer quién de los cuatro capitanes generales que debía tener la nación, fungiría como Generalísimo para los casos ejecutivos y de combinación. Era algo así como un mando supremo al cual quedarían subordinados los capitanes generales y el resto de la oficialidad. Además, consideró que dicha investidura no le confería graduación ni aumento de salario y que cesaría en sus funciones al término de la guerra, pudiéndole remover del mismo modo que entró ${ }^{42}$. Rayón buscaba con ello limitar la concentración de poder en un solo hombre, ante el temor de que pudiera degenerar en despotismo.

Cuando Morelos conoció el documento objetó algunos puntos. Según él, bastaba con que hubiera uno o dos capitanes generales, dos tenientes generales, tres mariscales, tres brigadieres y si acaso, un cuartel maestre general y un intendente general de ejército. Tampoco era partidario de que hubiera muchos brigadieres en el Consejo, sino un número determinado de ellos. Argumentaba que si permanecían repartidos en lugares distantes, la reunión no podría verificarse con la prontitud que el caso lo demandaba. Para terminar, sugirió que el Generalísimo continuara en su empleo más tiempo, el cuál dejaría de serlo sólo por ineptitud ${ }^{43}$.

Más adelante, en otra circular que difundió desde el puerto de Acapulco, Morelos precisó que para la elección del Generalísimo «votarán por escrito de coroneles para arriba cuantos estén en servicio de las armas, de los cuatro capitanes generales conocidos hasta ahora, el que juzguen más idóneo y capaz

42 Rayón a Morelos, Zinacantepec, 30 de abril de 1812, en Lemoine Villicaña, 1965: 222225.

43 Morelos a Rayón, Tehuacán, 7 de noviembre de 1812, ibidem: 226, 228. 
de dar completo lleno al pesado y delicado cargo que va a poner en sus manos». También votarían los electores de cada parroquia que se dieran cita en Chilpancingo y lo mismo harían los diputados «de cuya pluralidad de votos resultará legítimamente electo el Generalísimo de las armas y asentado el Poder Ejecutivo, atributo de la soberanía.... ${ }^{44}$.

Todo lo que pensaba Morelos con respecto al rol que debía jugar el Generalísimo en tiempos de guerra quedó plasmado en el Reglamento del Congreso, aquel que fue dictado por Andrés Quintana Roo y suscrito por el caudillo el 11 de septiembre de 1813 en Chilpancingo. En él se decía que el Poder Ejecutivo, uno de los tres constitutivos de la soberanía, recaería en el general «que resultase electo Generalísimo» (art. 14). A él correspondería hacer cumplir los decretos expedidos por el Congreso, estampando su firma en los mismos (arts. 25 y 26). Podría presentar iniciativas de ley ante la asamblea y vetar aquellas que le parecieran injustas o impracticables (art. 27) y si el caso lo demandara, tenía que aprobar la sentencia dictada contra cualquier diputado acusado de «infidencia a la patria o a la religión» (art. 31). Otro artículo especificaba la permanencia en el empleo, las razones para sustituirle y la manera como debería ser elegido:

Durará el Poder Ejecutivo en la persona del Generalísimo todo el tiempo que esté apto para su desempeño, y faltando éste por muerte, ineptitud o delito, se elegirá otro del cuerpo militar, a pluralidad de votos de coroneles arriba, y entre tanto recaerá el mando accidental en el segundo y tercero que hubiere nombrado, y si no los hubiere, recaerá en el de más graduación de actual ejercicio (art. 45).

Además, el Generalísimo obraría «con total independencia» de los otros dos Poderes y podía conferir o quitar graduaciones, honores y distinciones (art. 46), pero sería el Congreso el encargado de facilitarle «cuantos subsidios pida de gente o de dinero para la continuación de la guerra» (art. 47). La única instancia de autoridad a la que el Generalísimo estaba obligado a rendir cuentas era al Congreso (art. 46). Sólo podría ser juzgado por delitos similares a los de los representantes con sentencia aprobada por los otros dos Poderes (art. 34), mientras que todos aquellos que fueran sus subalternos y que cometieran «delitos gravísimos, estarán sujetos al consejo de guerra y en los graves y leves a las penas que señala la Ordenanza» $(\operatorname{art} .35)^{45}$.

44 Orden circular de Morelos, Cuartel general en Acapulco, 8 de agosto de 1813, en Lemoine Villicaña, 1963: 653-654. Herrejón Peredo, 2015, vol. I: 389-391.

45 Reglamento del Congreso, Chilpancingo, 11 de septiembre de 1813, en Lemoine Villicaña, 2013: 132-144. Herrejón Peredo, 2015, vol. I: 395-398. 
Morelos: «Generalísimo de laS ARMAS DE LA AMÉRICA SEPTENTRIONAL»

Tuvieron que pasar más de dos años a partir de la muerte de Hidalgo, para que el 15 de septiembre de 1813 el antiguo vocal de la Suprema Junta Nacional Americana, José María Morelos y Pavón, el más afamado estadista y táctico militar que produjo la insurgencia, fuera designado por los diputados del Congreso de Chilpancingo, «Generalísimo de la armas de la América Septentrional».

Es pertinente recordar que como resultado de la entrevista que sostuvo con Hidalgo en el trayecto de Charo a Indaparapeo aquel 20 de octubre de 1810 , Morelos había sido comisionado para recorrer las tierras calientes del sur y procurar en lo posible la conquista del puerto de Acapulco. Se dice que él quería servir de capellán, pero el jefe de la insurrección lo nombró su lugarteniente ${ }^{46}$. Para el 17 de noviembre siguiente, Morelos se hacía llamar teniente o lugarteniente del excelentísimo señor Miguel Hidalgo ${ }^{47}$, a mediados de abril de 1811 fundó la provincia de Tecpan como «general de los ejércitos americanos para la conquista de las provincias del sur» ${ }^{48}$, y en octubre, firmaba como «teniente general de ejército y general en jefe de los del sur» ${ }^{49}$.

Hasta aquí, con excepción del primero de sus títulos, el resto los fue consiguiendo con base en sus victorias y logros en campaña, pues no consta que Hidalgo o Allende a quienes Morelos a veces invocaba, los expidieran. Fue hasta el mes de junio de 1812 cuando la Suprema Junta, gobierno formalmente instituido para coordinar los proyectos políticos y bélicos de la insurgencia, le concedió el título de capitán general y junto con él el de vocal del mismo organismo $^{50}$. Tal empleo militar habría de mantenerlo hasta mediados de septiembre de 1813 en que llegó la hora de elegir al nuevo Generalísimo.

La designación de Morelos se realizó conforme a lo estipulado en el $R e$ glamento del Congreso, aunque también se tomó en cuenta lo que el ex presidente Rayón había marcado en sus Elementos Constitucionales. Esto lo podemos observar en la «lista de insurgentes que dieron su voto a Morelos para que fuese electo Generalísimo», publicada por Hernández y Dávalos, la

46 Declaración de Morelos, México, 28-30 de noviembre de 1815, en Lemoine Villicaña, 1965: 640. Herrejón Peredo, 2015, vol. I: 128-132.

47 Bando de Morelos, Cuartel general del Aguacatillo, 17 de noviembre de 1810 y Morelos al capitán de la fragata Guadalupe, Cuartel general del Aguacatillo, 19 de noviembre de 1810, en Lemoine Villicaña, 1965: 162-163.

48 Orden de Morelos, Ciudad de Nuestra Señora de Guadalupe, 18 de abril de 1811, en Lemoine Villicaña, 1965: 172. Herrejón Peredo, 2015, vol. I: 151.

49 Orden de Morelos, Tecpan, 13 de octubre de 1811, en Lemoine Villicaña, 1965: 181.

50 Morelos a Liceaga, Cuartel general en Chilapa, 28 de junio de 1812, en Lemoine Villicaña, 1965: 203. Herrejón Peredo, 2015, vol I: 288. 
cual incluía a 2 tenientes generales, 5 mariscales de campo, 7 brigadieres, 26 coroneles, 3 tenientes coroneles así como una variedad de funcionaros y asistentes vinculados al sector castrense, entre los que figuraban inspectores generales, comisarios de guerra y capellanes de ejército ${ }^{51}$.

Aunque Morelos se rehusó en un principio a convertirse en el principal jefe militar de las fuerzas insurgentes, al final los legisladores del Congreso y el voto de los militares que en aquella ciudad estaban reunidos, lo hicieron aceptar el cargo. Sin embargo, el caudillo puso cuatro condiciones: primero, que cuando vinieran tropas extranjeras a auxiliarlos no estuvieran cerca de la sede de la Suprema Junta, para evitar un posible golpe de Estado. En seguida, que en caso de muerte del Generalísimo debía ser nombrado el jefe más inmediato de los nombrados por él. Después, que nadie debía negar los auxilios que pidiera, y finalmente, que a pesar de su muerte se debía mantener la unidad del ejército. Aceptado todo esto por los diputados, Morelos y su secretario Juan Nepomuceno Rosáins juraron el cargo ${ }^{52}$.

Se sabe que Morelos renunció a privilegios y títulos rimbombantes como el de «Su Alteza Serenísima» y que prefirió ser llamado «Siervo de la Nación», razón por la cual fue objeto de críticas y comentarios irónicos por parte de su acérrimo enemigo, el virrey Félix María Calleja. Lo que quizá es menos conocido es que, tres días después de haber sido votado por los militares para ocupar el cargo de Generalísimo, de ser aclamado por todo el pueblo reunido en Chilpancingo e invitado por los propios diputados del Congreso para quedar al frente de aquel ejército, con ese espíritu de desprendimiento que le caracterizaba, Morelos ofreció a Rayón el empleo con el que lo «ha condecorado la nación» ${ }^{53}$. De esta manera confirmaba lo que le había dicho al abogado en una carta, poco antes de la instalación del Congreso: que no pretendía la presidencia, que sus funciones cesarían establecida la asamblea y que se tendría por muy honrado con el epíteto de «humilde Siervo de la Nación». Sin embargo, en aquel contexto, el empleo de Generalísimo se asoció al de representante del Poder Ejecutivo, para dar cabida al principio de separación de poderes que el mismo Morelos había promovido cuando forzó la reforma de la Suprema Junta ${ }^{54}$.

${ }^{51}$ Lista de insurgentes que votaron a Morelos Generalísimo, Chilpancingo, 25 de septiembre de 1813, en Hernández y Dávalos, 1985, tomo V: 177-179. Lemoine Villicaña, 1963: 531-535.

52 Designación del Generalísimo, Chilpancingo, 15 de septiembre de 1813, en Guedea, 1995: 95-96. Herrejón Peredo, 2015, vol. I: 422-423. Ver el documento completo en Lemoine Villicaña, 1965: 374-375.

53 Morelos a Rayón, Chilpancingo, 18 de septiembre de 1813, en Guedea, 1995: 96.

54 Herrejón Peredo, 2015, vol. I: 393-394. 
El retrato que este último se mandó hacer en Oaxaca a finales de 1812 nos da una idea de las características del uniforme que utilizó cuando era capitán general, pero poco se sabe del vestuario y divisas que comenzó a utilizar cuando fue electo Generalísimo. Es probable que Morelos siguiera empleando dicho atuendo en vez del de teniente general, que era de menor rango, no obstante sus 22 llamativos botones de oro macizo. Se sabe de cierto que fue un regalo de Matamoros, quien lo mandó hacer en la capital de la antigua Antequera, que era de «costosos bordados» y que portaba como divisa una banda celeste de Generalísimo, un bastón de plata compuesto de cuatro piezas con empuñadura de oro que tomó en Oaxaca y un espadín con puño también en oro ${ }^{55}$. Todos estos objetos fueron capturados por los realistas en febrero de 1814 luego de la acción de Las Ánimas, cerca de Tlacotepec, en el actual estado de Guerrero.

¿Qué hizo Morelos en su papel de Generalísimo? Prácticamente todo aquello que estipulaba el Reglamento del Congreso. El 18 de septiembre de 1813 anunció a los habitantes de Tecpan, Oaxaca, México, Puebla, Veracruz y Tlaxcala, su designación como «Generalísimo encargado del Poder Ejecutivo». Además, les comunicó el nombramiento de Mariano Matamoros como comandante en jefe del Ejército del Sur y las penas a que se hacían acreedores quienes no sacrificaran su persona e intereses en beneficio de la patria ${ }^{56}$. Enseguida emplazó a Rayón, Liceaga y Cos, presidente, vocal y vicario castrense respectivamente de la antigua Junta, para que en un plazo de entre 40 y 50 días acudieran a Chilpancingo a ocupar su asiento en el reformado Congreso ${ }^{57}$. Después, el 5 de octubre ordenó «que los pueblos y repúblicas hagan sus elecciones libres, presididas del párroco y juez territorial», aboliendo la «distinción de castas» ${ }^{58}$. Así como concedió a Manuel Muñiz la comandancia general de Michoacán, Guanajuato, Guadalajara y San Luis Potosí, de igual modo nombró a Ramón Rayón comandante general de la demarcación

55 Nota de las alhajas y muebles que el virrey de Nueva España remite al excelentísimo señor ministro de la Guerra para que se sirva tenerlo a disposición de su alteza la Regencia del reino, México, 30 de abril de 1814, AGN, Correspondencia de virreyes, tomo 268-A, n. ${ }^{\circ}$ 32, f. 107.

56 Proclama de Morelos, Chilpancingo, 18 de septiembre de 1813, en Lemoine Villicaña, 1965: 379-380. Boletín expedido por Nicolás Bravo, sin lugar, 13 de octubre de 1813, ibídem: 398.

57 Morelos a Bustamante, Chilpancingo, 17 de septiembre de 1813, en Lemoine Villicaña, 1963: 527-528. Diario de gobierno y operaciones militares de la secretaría y ejército del Exmo. Sr. presidente de la Suprema Junta y ministro Universal de la nación, Lic. don Ignacio López Rayón, 26 de septiembre de 1813, en Rayón, 1856: 39.

58 Decreto de Morelos, Chilpancingo, 5 de octubre de 1813, en Lemoine Villicaña, 1965: 384-385. 
de Tlalpujahua, confiriéndole además el título de mariscal de campo ${ }^{59}$, y conforme al artículo 46 del Reglamento emitió en el campo de Chupio, camino a Valladolid, el decreto del 16 de diciembre sobre divisas, con el objeto de incentivar el espíritu guerrero en todos aquellos que marchaban a la conquista de la ciudad donde había nacido ${ }^{60}$.

El beneplácito que generó entre la población que Morelos se alzara con aquel empleo fue evidente, pues hasta los Guadalupes de la ciudad de México le mandaron sus felicitaciones por haber sido nombrado «Generalísimo de las armas americanas» ${ }^{61}$. Aún aquellos con los que el caudillo del sur había tenido serias discrepancias se sometieron a su autoridad. Rayón por ejemplo, antiguo presidente de la Suprema Junta, con toda formalidad se dirigía a él como «el Generalísimo señor Morelos» y cuando el abogado se encontró con aquel caudillo en Chilpancingo tuvieron tiempo de charlar en el «palacio de Su Alteza Serenísima» ${ }^{62}$.

Por otro lado, en el interrogatorio que se le hizo estando preso, Morelos dijo que ostentó el cargo de Generalísimo durante tres meses, pero esta información no es del todo precisa, ya que después de la derrota que sufrió en Valladolid y posteriormente en Puruarán, en la Tierra Caliente de Michoacán, continuó haciendo uso de ese nombramiento. Así, vemos que el 24 de enero propuso al virrey Calleja un canje de 200 prisioneros españoles a cambio de la vida de Matamoros sin tener éxito ${ }^{63}$, y al día siguiente firmó varias comisiones desde «el cuartel generalísimo en Coyuca» (hoy de Catalán), en el actual Guerrero ${ }^{64}$.

Otra función desempeñada por Morelos consistió en «regenerar el gobierno» reformando el Congreso y ampliando la representación nacional a través de diferentes diputados titulares y suplentes ${ }^{65}$. Inclusive el 21 de febrero de 1814 en Tlacotepec, hizo uso de su derecho de iniciativa al proponer al licen-

59 Diario de gobierno..., 9 y 15 de octubre de 1813, y 8 y 9 de noviembre de 1813, en Rayón, 1856: 40, 41.

60 Decreto de Morelos, Campo de Chupio, 16 de diciembre de 1813, Centro de Estudios de Historia de México-Carso, Ciudad de México (CEHM-Carso), fondo CMLXI-40, 1813, exp. 17-21.

${ }^{61}$ Los Guadalupes a Morelos, [México], 3 de noviembre de 1813, en Lemoine Villicaña, 1965: 419-420.

62 Diario de gobierno..., 17 de octubre de 1813 y 3 de noviembre de 1813, en Rayón, 1856: 40.

${ }^{63}$ Morelos a Calleja, Cuartel generalísimo en Coyuca, 24 de enero de 1814, en Lemoine Villicaña, 1965: 456.

${ }^{64}$ Herrejón Peredo, 1987: 336-338.

65 Morelos a Quintana, Huacura [Huacario], 18 de mayo de 1814, en Rodríguez Tapia, 2013: 99. 
ciado Manuel Alderete y Soria para que ocupara el empleo de «vocal en el Supremo Congreso Nacional» por la provincia de Querétaro, como finalmente sucedió ${ }^{66}$.

No pararon ahí las actividades del Generalísimo. A finales de marzo publicó un bando anunciando lo difícil que era sostener el puerto de Acapulco y lo gravoso que resultaba a los vecinos de Huetamo la custodia de la fortaleza, por lo que ordenó abandonarla ${ }^{67}$. A mediados de junio atendió problemas de tierras desde su «cuartel generalísimo en Aguadulce» y poco después dictó medidas contra la rapiña y los excesos de algunos oficiales desde su «cuartel generalísimo en Los Sauces». En la tercera semana de julio dio nombramiento de mariscal de campo a Nicolás Bravo ${ }^{68}$ y para el 26 de agosto siguiente, mantenía correspondencia con dicho militar sobre el conflicto que había surgido entre su secretario Rosáins y el general Rayón ${ }^{69}$.

Ahora bien, aunque Morelos había alcanzado el título de Generalísimo apoyado en tres fuentes de legitimidad (el voto de los diputados, la aclamación del pueblo y el respaldo militar), no escapó a las críticas y señalamientos de algunos de sus contemporáneos por la manera en que quiso imponer la disciplina y el orden en su ejército. En una carta que remitió a los vocales José Sixto Berdusco y José María Liceaga, advirtiéndoles de otra que envió a Rayón, les dijo: «Se me ha informado que entre los compañeros tengo el epíteto de déspota», a lo que enseguida respondió: «El no tener yo capitán sin compañía, coronel sin regimiento, brigadier sin brigada, no arguye despotismo, sino buen orden $\rangle^{70}$.

Si bien Morelos tenía razón en actuar con energía en ese rubro, lo que sorprende es que no se haya mantenido en esa postura todo el tiempo que estuvo como jefe máximo de la insurgencia. No le importó sobajar la autoridad de Rayón como presidente de la Suprema Junta, convocando a un nuevo Congreso con sede en Chilpancingo, ni que aquel le echara en cara la «preponderancia de sus bayonetas» para reformar el gobierno. Morelos, asesorado por su secretario Rosáins, clausuró sin miramientos la existencia de dicho organismo. En cambio, cuando el Supremo Congreso decidió arrebatarle el

${ }^{66}$ Morelos a Alderete, Tlacotepec, 21 de febrero de 1814, en Hernández y Dávalos, 1985, tomo V, n. ${ }^{\circ}$ 65: 158. Guedea, 1995: 472.

${ }^{67}$ Bando de Morelos, Cuartel generalísimo en el campo donde era Acapulco, 26 de marzo de 1814, en Lemoine Villicaña, 1965: 466-467.

68 Herrejón Peredo, 1987: 336-338, 340.

${ }^{69}$ Morelos a Bravo, Cuartel generalísimo en Aguadulce, 26 de agosto de 1814, en Lemoine Villicaña, 1965: 485-486.

70 Morelos a Berdusco y Liceaga, Veladero, 28 de marzo de 1813, en Guedea, 1995: 76. 
Poder Ejecutivo luego del doble desastre de Valladolid-Puruarán y dejarle el título honorífico de Generalísimo, Morelos no protestó y se limitó a responder que «cuando el señor habla, el siervo debe callar». A pesar de sostenerle el nombramiento, para los señores diputados había ocurrido lo que el mismo Morelos escribió en el artículo 45 del Reglamento del Congreso: el Generalísimo dejaba de serlo por ineptitud, no por muerte ni traición a la patria ${ }^{71}$.

Como vemos, Morelos jamás renunció a aquel título a pesar de que ya para 1815 sus fuerzas armadas habían mermado considerablemente ${ }^{72}$, todavía en marzo de aquel año, empleados de la tesorería insurgente se dirigían a él como «el señor Generalísimo» ${ }^{73}$. El propio virrey Félix María Calleja en una carta reservada que le remitió al ministro de Indias, le expuso que Morelos, «por su genio audaz y emprendedor y por su opinión ascendente $\mathrm{y}$ ascendiente sobre todos los cabecillas que nuevamente le habían adjudicado el carácter de Generalísimo, era el único capaz de llevarlos a cabo y de darles la unidad y concierto indispensable para su ejecución $\gg{ }^{74}$. Por eso celebró tanto su captura y posterior fusilamiento el 22 de diciembre de 1815 en Ecatepec.

Luego de la muerte del prócer no hubo un jefe con la suficiente autoridad política, militar y moral para aglutinar y subordinar a una diversidad de cabecillas rebeldes, que de manera independiente actuaban en distintas demarcaciones del virreinato ${ }^{75}$. La Junta Subalterna Gubernativa, creada por el Supremo Congreso Mexicano antes de su disolución, trató de suplir ese liderazgo institucional, pero a lo más que llegó en el plano militar fue a reconocer los títulos que ya tenían los antiguos jefes y oficiales y a expedir nuevos despachos. Sin embargo, ninguno de ellos correspondió al título de Generalísimo.

En una obra reciente, Ortuño y Gil Novales afirman que en 1817 la Junta de Jaujilla le concedió a Xavier Mina el despacho de «Generalísimo del ejército insurgente en la zona del Bajío», pero que éste no lo llegó a ejercer debido a su prematuro fusilamiento en el cerro del Bellaco en noviembre de aquel año ${ }^{76}$. Es probable que exista una confusión en ambos autores, pues tal título, si es

71 Reglamento del Congreso, Chilpancingo, 11 de septiembre de 1813, en Lemoine Villicaña, 2013: 142. Sobre las diferencias entre Morelos y el Congreso, véase Herrejón Peredo, 2013: 99-107.

${ }^{72}$ Lemoine Villicaña, 2014: 86-89.

73 Herrejón Peredo, 1987: 359.

74 Ibidem: 368.

75 Lemoine Villicaña, 2014: 86-87.

76 Mina Larrea, 2012: 126. 
que se dio, no podía limitarse a una sola demarcación —-la del Bajío-, ya que abarcaba a todas las fuerzas de mar y tierra que apoyaban la independencia.

\section{ITURBIDE: «GENERALÍSIMO DE LAS ARMAS DE MAR Y TIERRA Y ALMIRANTE»}

Con la proclamación del Plan de Independencia el 24 de febrero de 1821 en la villa de Iguala dio inicio otro movimiento, distinto al de 1810, al que tocaría alcanzar el anhelo de los primeros caudillos insurgentes ${ }^{77}$. Fue encabezado por Agustín de Iturbide, un antiguo oficial realista de origen criollo descendiente de una familia bien relacionada entre la élite política de Valladolid, capital de la intendencia homónima. Su carrera militar comenzó en octubre de 1797 a la edad de 14 años cuando su padre José Joaquín de Iturbide y Arregui compró para él el título de subteniente de bandera del primer batallón del Regimiento Provincial de Valladolid que organizó Diego Rul78.

Dice Iturbide en su Manifiesto al mundo... que poco después de que inició la revolución, siendo apenas teniente de un cuerpo provincial en el que no recibía sueldo alguno, Hidalgo le ofreció la faja de teniente general, misma que rechazó porque se dio cuenta que «los planes del cura estaban mal concebidos» ${ }^{79}$. El historiador Anastasio Zerecero ofrece otra versión que dio a conocer muchos años después: dice que debido a que Joaquín de Iturbide, padre de Agustín, fue aprehendido por los insurgentes cuando pasaron por Valladolid, éste último se vio obligado a aceptar el empleo de capitán, el cual el propio Hidalgo aprobó ${ }^{80}$. Sin embargo, ningún otro autor ha podido confirmar este aserto. En cambio, sabemos por la Correspondencia y diario de Iturbide que ante el asedio insurgente, desde la tarde del 5 de octubre se dirigió a Acámbaro por el camino de Indaparapeo con la intención de atacar a los rebeldes, pero al ver la superioridad en número se escondió en una casa en Maravatío y posteriormente optó por trasladarse a la capital del virreinato a donde llegó días después ${ }^{81}$.

77 Sobre las distintas versiones del Plan, véase Arenal Fenochio, 2013: 91-116.

78 Propuestas de empleos, México, 2 de octubre de 1797, Archivo General de Simancas, Simancas, Valladolid, España (AGS), Guerra Moderna, leg. 7005, exp. 1, fol. 37. Hoja de servicios de Agustín de Iturbide, diciembre de 1798, AGS, Guerra Moderna, leg. 7274, exp. 19, fol. 32. Hoja de servicios de Agustín Iturbide, diciembre de 1800, AGS, Guerra Moderna, leg. 7276 , exp. 3 , fol. 31 .

79 Iturbide, 2001: 38-39.

80 Zerecero, 1975: 94, nota 3.

81 Iturbide al virrey Venegas, Maravatío, 8 y 16 de octubre de 1810, "Correspondencia y diario militar de Agustín de Iturbide, 1810-1813”, Boletín del Archivo General de la Nación, 1923, tomo I: 2-4. 
Luego encontramos a Iturbide en la batalla del monte de las Cruces como teniente a las órdenes de Torcuato Trujillo (noviembre de 1810) ${ }^{82}$. A principios de junio de 1812 había ascendido a capitán y actuaba por el rumbo de Salamanca y Valle de Santiago bajo el mando de Diego García Conde, quien perseguía al insurgente Albino García ${ }^{83}$, y dos meses más tarde aparece ya como teniente coronel sujeto al mismo comandante haciendo incursiones por el rumbo de Valtierrilla, Valle de Santiago y Yuriria, en la intendencia de Guanajuato ${ }^{84}$.

Cuando Iturbide enfrentó a Ramón Rayón en el puente de Salvatierra (abril de 1813) conservaba el mismo nombramiento y mandaba en jefe una sección de la división del brigadier García Conde, teniendo a sus órdenes un cuerpo de Artillería, el destacamento de la Corona, el Batallón Mixto, el cuerpo de Frontera, el Escuadrón de San Carlos, el de Lanceros de Francisco Orrantia y el Piquete de Dragones de San Luis ${ }^{85}$. Su último ascenso como oficial realista lo conseguiría precisamente después de esa batalla, pues le fue conferido el «empleo efectivo de coronel comandante del Batallón Provincial de Infantería de Celaya, que deberá organizarse según el nuevo reglamento, nombrándole al mismo tiempo comandante de todas las tropas del Bajío y de la provincia de Guanajuato», mientras que a sus oficiales y soldados se les concedió un escudo con el lema: "Venció en el Puente de Salvatierra»"

Con ese empleo se mantuvo Iturbide hasta los años finales de la guerra y se prolongó durante los siete meses que duró la campaña militar del Ejército Imperial de las Tres Garantías. La única diferencia fue que en esta última etapa, todos sus subordinados se dirigían a él como general, primer jefe o general en jefe de dicho Ejército, cuyas fuerzas harían su entrada triunfal a la ciudad de México el 27 de septiembre de 182187. Muchos epítetos le dieron a Iturbide en ese entonces, como lo registra Javier Ocampo en su obra, pero ninguno fue tan importante como el que le concedió el 28 de septiembre la Soberana Junta Provisional Gubernativa al designarlo Generalísimo de las Armas de Mar y Tierra y Almirante ${ }^{88}$.

Tal distinción implicó una modificación en las insignias que en adelante deberían usar tanto Iturbide con su nuevo cargo, como los demás jefes y oficiales subalternos. De acuerdo con el Reglamento de divisas del Ejército

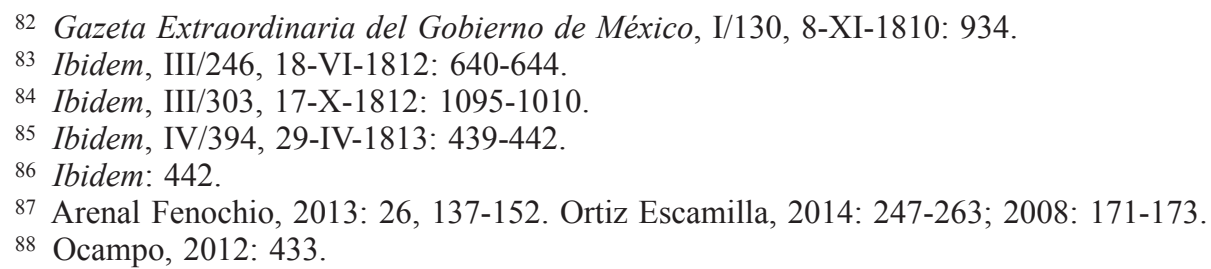


Imperial Mejicano del mes de octubre, a través del cual se reformaron muchas de las que anteriormente usaban los jefes y oficiales realistas, las insignias que debía portar el Generalísimo serían charreteras de oro, faja celeste y sobre las charreteras un sol bordado de piedras. También usarían divisas diferentes el coronel efectivo y el coronel graduado, cuya única diferencia era una estrella de color contrario al de la pala que se mostraba en un diseño hecho exprofeso. En los dragones de caballería sobresalían las armas americanas del arco y flecha, además del casco y un par de sables, mientras que los oficiales del Estado Mayor llevarían como divisa un águila coronada con las alas extendidas ${ }^{89}$.

A partir de octubre de 1821, la figura del Generalísimo se popularizó entre la gente y hasta los propios oficiales comenzaron a dirigirse a él de esa manera a través de piezas poéticas, impresos y correspondencia. Juan Nepomuceno Troncoso, aquel que imprimió en Puebla la tercera edición del Decreto Constitucional de Apatzingán, se refería a Iturbide como «nuestro adorado Generalísimo» ${ }^{90}$; el teniente coronel Felipe Codallos que estaba al frente del Batallón de Línea de Santo Domingo que residía en esa misma intendencia, comenzó a darle el tratamiento de «excelentísimo señor Generalísimo don Agustín de Iturbide» ${ }^{91}$, y el coronel Miguel Torres comandante militar de Querétaro, se dirigía a él como «serenísimo señor don Agustín de Iturbide, Generalísimo Almirante de las armas del Imperio» ${ }^{92}$. Lo más significativo fue que, en no pocas poblaciones, en los teatros de las ciudades y en las concurrencias públicas donde Iturbide llegó a estar presente o salía a relucir su nombre, comenzó a ser vitoreado y proclamado emperador ${ }^{93}$.

Ya en su calidad de Presidente de la Regencia y «Generalísimo de las armas de mar y tierra de este Imperio», Iturbide se ocupó de atender una variedad de asuntos que demandaba su investidura. Primeramente, renovó los bandos del 30 de junio y 20 de julio que había expedido como Primer Jefe del Ejército Trigarante, relativos a la reducción de alcabalas y requisición de armas, respectivamente ${ }^{94}$. Además, donó al Ejército la cuantiosa suma de 71 mil pesos de los 120 mil que dicha Soberana Junta le había asignado como

89 Reglamento, 1821, Biblioteca Nacional de México, Ciudad de México (BNM), Fondo Lafragua, 308.

90 Guzmán Pérez, 2014: 24.

91 Codallos a Iturbide, Puebla, 10 de octubre de 1821, en Alessio Robles, 1945, tomo I: 5.

92 Torres a Iturbide, Querétaro, 9 de enero de 1822, en ibidem, tomo II: 84.

93 Ocampo, 2012: 101, 125.

94 http://cdigital.dgb.uanl.mx/la/1020134691/1020134691_002.pdf (consultado el 2-X2016). 
sueldo, gesto que el 18 de octubre de 1821 fue declarado por ésta como «de mérito calificado» ${ }^{95}$. Dos días después, el mismo cuerpo colegiado decretó

... que habiendo servido ahora los empleos y dignidades de Generalísimo y Almirante para condecorar al autor de la Independencia de este Imperio, el excelentísimo señor don Agustín de Iturbide, y no pudiéndose ver ocupados en lo sucesivo tan dignamente como ahora; cuando vaquen se supriman perpetuamente, sin que puedan renovarse ni conferirse a persona alguna de cualquiera clase que sea ${ }^{96}$.

Mientras eso ocurría, otro decreto en 15 artículos expedido por la Soberana Junta el 14 de noviembre siguiente fijó las prerrogativas, facultades y honores que debía tener Iturbide por sus empleos de Generalísimo Almirante. Mientras la nación no eligiera a su emperador, en Iturbide quedó concentrado el mando de todas las fuerzas de mar y tierra, pudiendo intervenir en su gobierno económico conforme a las leyes. Además, dirigiría la instrucción de colegios militares y de cuerpos armados del Ejército y Marina, facultándolo para inspeccionar las fábricas de pólvora, armas, municiones y vestuarios del Ejército así como arsenales, astilleros y fábricas de la Marina. También, vigilaría la hacienda militar de mar y tierra, podía distribuir y mover las fuerzas marítimas y terrestres conforme a las órdenes dictadas por el emperador, protegería el comercio, la navegación y las plazas del Imperio con las facultades de Almirante y expediría pasaportes y licencias para navegar de acuerdo con las órdenes del soberano. Con Iturbide estarían vinculados el secretario de Guerra, Marina y Hacienda y se apoyaría en dos generales nombrados por él, quienes serían los responsables de hacer cumplir sus órdenes y mantener comunicación con los demás secretarios de Estado.

Así mismo, Iturbide estuvo facultado para nombrar un tercer general como responsable del Estado Mayor de Marina cuando éste se formase, se le daría el tratamiento de Alteza, su guardia personal se compondría de dos compañías de Infantería con bandera, «la que le presentará armas y batirá marcha», con la particularidad de que dicha guardia sólo podía hacer honores a las personas de la familia imperial. Cada vez que saliera, cuatro batidores marcharían delante de él, seguido de una escolta de veinte hombres mandados por su oficial. También recibiría honores por los puestos de la plaza cada vez que visitara la Corte y residencia del emperador. Finalmente, cada vez que entrara y saliera de plazas y guarniciones se le formaría la tropa, la artillería dispararía 21 2016)

95 http://cdigital.dgb.uanl.mx/la/1020134691/1020134691_006.pdf (consultado el 25-V96 Idem. 
cañonazos «teniendo en todo lo demás en mar y tierra los supremos honores militares ${ }^{97}$.

Otro decreto expedido por la Soberana Junta al día siguiente, le concedió los honores de «Regente del Imperio», título que en algún momento gozó su padre José Joaquín, y le asignó un sueldo anual de 10 mil pesos, ordenando que dicha disposición se cumpliera casi de inmediato.

Uno de los asuntos más delicados que tuvo que atender Iturbide como Generalísimo, fue el de la aprehensión de varios individuos que habían conspirado contra el gobierno y de la sumaria que les había instruido, de todo lo cual notificó a la Soberana Junta ${ }^{98}$. También, ordenó recoger folletos subversivos que circularon en la capital con el título de Consejo prudente sobre una de las Garantías atacando una de ellas, lo cual hizo que Iturbide retrasara el correo y publicara un bando reivindicativo que circularía por todo el Imperio. Por último, mandó imprimir la representación de los militares que habían capturado los folletos para demostrar con ello el decidido empeño de la Junta y del Gobierno por hacer cumplir el Plan de Iguala y los Tratados de Córdoba.

Posteriormente, en enero de 1822, el Generalísimo se dirigió a Carlos de Urrutia, teniente general del ejército español y presidente de la Audiencia de Guatemala, para comunicarle la determinación de la Soberna Junta de rechazar su petición de anexar aquel territorio al Imperio Mexicano, «por no ser conforme al sistema y principios liberales que la distinguen ${ }^{99}$. De igual modo, se le comisionó para gestionar un préstamo por un millón y medio de pesos, hipotecando las rentas del Imperio que estimara convenientes.

El 9 de enero de 1822, a petición del Generalísimo, se decretó la suspensión de pasaportes para salir del territorio, ordenó el registro de buques en el puerto de Veracruz y delimitó las atribuciones de los militares que ocuparían las seis capitanías generales que pensaba crear en el Imperio. El 24 de ese mismo mes, el Colegio de San Ildefonso propuso a la Soberna Junta que en el Generalísimo recayesen las facultades que antes gozaban los virreyes, pero el cuerpo representativo regresó el asunto a la Regencia para que determinara al respecto y no se sabe cuál fue su resolución final. Por último, Iturbide atendió los problemas que ocasionó el bergantín Araucano y fijó los sueldos que se debían pagar a los empleados que radicaban en la provincia de Texas ${ }^{100}$.

97 http://cdigital.dgb.uanl.mx/la/1020134691/1020134691_009.pdf (consultado el 25-V2016). Ocampo, 2012: 437.

98 Ortiz Escamilla, 2014: 266.

$99 \mathrm{http} / / /$ cdigital.dgb.uanl.mx/la/1020134691/1020134691_017.pdf (consultado el 25-V2016)

100 Idem. 
Sin embargo, Iturbide poco pudo hacer con respecto al problema que representaba la fortaleza de San Juan de Ulúa, último reducto español defendido por el comandante José Dávila, porque las acciones emprendidas contra aquel sitio dependían de la voluntad e intereses de jefes locales como Antonio López de Santa Ana y Manuel Rincón ${ }^{101}$.

Desde luego, no faltaron los detractores que cuestionaron el proceder del Generalísmo así como las prebendas que se le concedieron por parte de la Soberana Junta, como fue el caso del publicista guayaquileño Vicente Rocafuerte. En su Bosquejo ligerísimo..., publicado de forma anónima en Filadelfia en 1822 , señaló que dicha Junta

... declaró a Iturbide Generalísimo Almirante de mar y tierra, con tratamiento de Alteza Serenísima y 120,000 pesos de sueldo anual, y le ofreció como por una especie de gratificación un millón de pesos en el valor de las fincas de la Inquisición, y veinte leguas cuadradas de terreno en una de las provincias de Tierra adentro. Hizo a su padre regente honorario con 10,000 pesos de sueldo [...] aprobó, o no reclamó los nombramientos de generales para las provincias, dados por la Regencia; otro tanto hizo con los ministerios de Guerra, de Hacienda, etcétera, con sueldos de 8,000 pesos cada uno. En una palabra, coartó aún las facultades y dio la ley al soberano Congreso futuro. Ninguna de estas decisiones eran ciertamente ejecutivas, pero ella las calificaba de tales y seguía maniobrando conforme a las miras de Iturbide... ${ }^{102}$.

\section{CONCLUSIONES}

Con la designación del primer Generalísimo en la época de la independencia comenzó en México la historia de los caudillos que de manera unipersonal y a veces dictatorial, ejercieron el poder supremo. A diferencia de los Generalísimos que en aquel tiempo hubo en Europa, como Manuel Godoy y Joaquín Murat, que estaban subordinados a Carlos IV y Napoleón Bonaparte, respectivamente, los que detentaron ese mismo título en Nueva España rápidamente se alzaron con el mando único. El estado de guerra en que se vivía contribuyó mucho a moldear su figura, convirtiéndolos en seres providenciales, carismáticos, justicieros, religiosos y patriotas. Aclamados por el pueblo, votados por sus representantes y apoyados por un cuerpo de jefes y oficiales que los defendían, estuvieron facultados para ejercer la ley y mantener el orden ante la anarquía producida por la guerra. Aunque su posición económica y actividad socio-profesional eran diferentes, algo en lo que todos coinci-

101 Ortiz Escamilla, 2008: 196, 208.

102 Rocafuerte, 1984: 117-118. 
dieron fue en su defensa de la fe católica ${ }^{103}$, en su anhelo de libertad y en la independencia de la patria, sólo que en momentos muy distintos.

Sin duda, existieron diferencias sobre la manera en que los caudillos de la independencia - insurgentes y trigarantes-, habían sido elegidos Generalísimos: Hidalgo fue respaldado por varios militares y «proclamado» por la nación desde los primeros días del movimiento. Allende alcanzó el cargo deponiendo a Hidalgo a la fuerza, con un ejército que acababa de ser derrotado, disperso y en franca retirada hacia el norte del territorio. Morelos en cambio, lo obtuvo apoyado en una legislación y a través de una elección, después de la cual fue aclamado por el pueblo, respaldado militarmente por decenas de jefes y oficiales con mando de tropa, en pleno auge de su carrera revolucionaria y con un Ejército del Sur victorioso que extendería sus triunfos hasta los límites con Guatemala. Su fama y poder, combinados con algunos reveses militares — como los de Valladolid y Puruarán-, lo llevaron a tener diferencias con el Supremo Congreso, al cual finalmente se subordinó. Por su parte, Iturbide sin dejar de ser coronel se convirtió en el Primer Jefe del Ejército Imperial de las Tres Garantías, siendo aclamado y vitoreado como el libertador de la patria a su entrada a la ciudad de México el 27 de septiembre de 1821, hasta que al día siguiente fue nombrado Generalísimo Almirante por la Soberana Junta Provisional Gubernativa, fungiendo a la vez como presidente de la Regencia. Aunque actuó con apego a la ley, entró en pugna con el primer Congreso Constituyente y poco después lo mandó disolver.

De los cuatro Generalísimos que registra la historia de México, sólo Morelos e Iturbide - ambos criollos y de origen vallisoletano- lograron adquirir sus títulos y ascensos militares por méritos de guerra, no obstante la formación clerical del primero. Ya en su papel de jefes máximos de sus respectivos ejércitos, fueron los que representaron por más tiempo el empleo, los que gozaron de un salario asignado por órganos legislativos y de gobierno y cuyas disposiciones en el ámbito político, militar y económico-administrativo, tuvieron mucha más trascendencia en su momento, a pesar de las críticas que hubo en el caso del segundo.

Más allá de que los tres Generalísimos que produjo la insurgencia hubiesen alcanzado o no los objetivos políticos y militares que se propusieron, lo que importa en este caso es conocer la forma como se comportaron cuando asumieron el poder supremo de las fuerzas rebeldes. Sólo de esta manera podremos comprender cómo se perfiló la figura del caudillo y se empezó a ejercer el poder unipersonal en México en aquel convulso siglo XIX.

103 Arenal Fenochio, 2013: 117-134. 
En síntesis, observamos en ellos una incesante búsqueda de legitimidad basada no solo en aspectos carismáticos, sino en la fuerza de las armas, en la práctica tradicional de la aclamación y en procesos dirigidos de elección. Aparece también una excesiva concentración de poder en un solo hombre, que para algunos rayó en despotismo; un uso arbitrario de su autoridad en situación de conflicto, el empleo de actos de fuerza para llegar al poder semejantes al de un golpe de Estado y una pugna constante con los Congresos y otros cuerpos legislativos con los que se disputaba el poder supremo. Varios de estos elementos fueron característicos de los hombres que fungieron como Generalísimos en aquel tiempo y fue así como se gestó el caudillismo en México.

El título de Generalísimo como máximo jefe militar responsable de conducir una guerra, quedó en desuso después de la abdicación de Iturbide como emperador de México, ocurrida el 19 de marzo de 1823. Tampoco se aplicó al triunvirato en el que recayó el ejercicio del Poder Ejecutivo representado por Nicolás Bravo, Pedro Celestino Negrete y Guadalupe Victoria; ni siquiera este último llegó a ostentar ese empleo cuando fue elegido presidente de México en 1824. Se había acatado el decreto de la Soberana Junta Provisional Gubernativa del 20 de octubre de 1821 que ordenó su extinción, pero no acabó con esa forma de ejercer el poder.

Tal distinción sería recordada únicamente en las exequias de aniversario, como cuando el doctor Francisco Argándar publicó su Elogio fúnebre exaltando los nombres de los tres Generalísimos que produjo la insurgencia ${ }^{104}$; o cuando se señaló el orden en que serían colocados los restos de los héroes de la independencia en el interior de la catedral de México, reuniendo así lo que quedó del «Serenísimo señor Generalísimo de las Armas don Ignacio Allende», del «Serenísimo señor Generalísimo de las Armas don Miguel Hidalgo y Costilla» y la osamenta entera del «Excelentísimo señor Generalísimo de las Armas don José María Morelos» ${ }^{105}$. Pero no se hizo lo mismo con la osamenta de Iturbide años después que murió.

La figura del Generalísimo en México estuvo muy presente en los actos cívicos conmemorativos cuando se festejaba el inicio o la consumación de la independencia, cuyos discursos impresos abundaron en los últimos dos siglos. Su nombre quedó escrito en los libros de historia patria de las escuelas de educación primaria de toda la república, a través de los cuales se inculcaba en la niñez valores cívicos y el culto a los héroes, perpetuando su recuerdo

104 Argándar, 1823: 7.

105 Ortuño Martínez, 2003: 352. 
en esculturas de mármol y bronce que adornan las plazas principales de muchas ciudades del país, como una manera de mantener viva en la memoria de los pueblos y de las futuras generaciones, las ideas y acciones de aquellos caudillos que dirigieron el proceso de emancipación.

\section{BIBLIOGRAFÍA}

Alessio Robles, Vito, La correspondencia de Agustín de Iturbide después de la proclamación del Plan de Iguala, México, Secretaría de la Defensa Nacional, 1945, 2 tomos. Colección Archivo Histórico Militar Mexicano, 1.

Alonso Baquer, Miguel, "La doctrina militar de los diputados de Cádiz", Revista de historia militar, 33 (Madrid, 1972): 139-154.

Arenal Fenochio, Jaime del, Un modo de ser libres. Independencia y constitución en México (1816-1822), México, INEHRM/El Colegio de Michoacán, 2010. Biblioteca del INEHRM.

Argándar, Francisco, Elogio fúnebre de los primeros héroes y víctimas de la patria, que el 17 de septiembre de 1823 en la iglesia metropolitana de México, a presencia de una diputación del Soberano Congreso, del Supremo Poder Ejecutivo, demás corporaciones y oficialidad..., México, Imprenta del Supremo Gobierno, 1823.

Arreola, Juan Federico, Teoría general de la dictadura. Reflexiones sobre el ejercicio del poder y las libertades políticas, México, Trillas, 2008.

Boletín del Archivo General de la Nación, México, Imprenta de Manuel León Sánchez, 1923-1930, 3 tomos.

Borreguero Beltrán, Cristina, Diccionario de historia militar. Desde los reinos medievales hasta nuestros días, Barcelona, Ariel, 2000.

Búlnes, Francisco, La Guerra de Independencia. Hidalgo-Iturbide, México, Talleres Linotipográficos de El Diario, 1910.

Casaús, fray Ramón, El Anti-Hidalgo. Cartas de un doctor mexicano al Br. D. Miguel Hidalgo y Costilla ex Cura de Dolores, ex Sacerdote de Cristo, ex Cristiano, ex Americano, ex Hombre y Generalísimo capataz de salteadores y asesinos, presentación y bibliografía por Masaé Sugawara, Morelia, Universidad Michoacana de San Nicolás de Hidalgo, Centro de Estudios sobre la Cultura Nicolaita, 1988. Colección Biblioteca de Nicolaitas Notables, 38.

García, Genaro, Documentos históricos mexicanos, México, Comisión Nacional para las celebraciones del 175 Aniversario de la Independencia Nacional y 75 Aniversario de la Revolución Mexicana/INEHRM, 1985, 7 tomos. [Edición facsimilar de la de 1910]. 
Godoy, Manuel, Mémoires du Prince de la Paix don..., traduits en français d'après le manuscrit espagnol par J. G. Deménard, Paris, Chez Ladvocat Libraire, 1836, 4 tomos.

González Casanova, José A., Dictadores y dictaduras, Barcelona, Las Ediciones del Tiempo, 1981.

Guedea, Virginia, Prontuario de los insurgentes, introducción y notas de..., México, Centro de Estudios sobre la Universidad/UNAM, Instituto Mora, 1995.

Guzmán Pérez, Moisés, Miguel Hidalgo y el gobierno insurgente en Valladolid, Morelia, Universidad Michoacana de San Nicolás de Hidalgo, Instituto de Investigaciones Históricas, 2011. Colección Bicentenario de la Independencia, 11.

Guzmán Pérez, Moisés, La Constitución de Apatzingán. Su historia editorial, Morelia, Casa Natal de Morelos/Frente de Afirmación Hispanista A. C./Universidad Nacional Autónoma de México/Universidad Michoacana de San Nicolás de Hidalgo, Instituto de Investigaciones Históricas, 2014.

Hernández y Dávalos, Juan E., Colección de documentos para la historia de la guerra de independencia de México de 1808 a 1821, México, Comisión Nacional para las celebraciones del 175 Aniversario de la Independencia Nacional y 75 Aniversario de la Revolución Mexicana/INEHRM, 1985, 6 tomos. [Edición facsimilar de la de 1877-1882].

Herrejón Peredo, Carlos, Morelos. Documentos inéditos de vida revolucionaria, México, El Colegio de Michoacán, 1987. Colección Biblioteca José María Morelos, I.

Herrejón Peredo, Carlos, "Escritos de Hidalgo publicados o datados en Guadalajara", Moisés Guzmán Pérez (coord.), Guerra e imaginarios políticos en la época de las independencias, Morelia, Universidad Michoacana de San Nicolás de Hidalgo, Instituto de Investigaciones Históricas, 2007: 23-57. Colección Bicentenario de la Independencia, 2.

Herrejón Peredo, Carlos, Hidalgo. Maestro, párroco e insurgente, México, Clío/Fomento Cultural Banamex, 2011.

Herrejón Peredo, Carlos, "Morelos y el Congreso", Luis Mendoza Cruz (comp.), Raíces históricas del constitucionalismo en México, México, Cámara de Diputados, LXII Legislatura, 2013: 89-112.

Herrejón Peredo, Carlos, Morelos, México, El Colegio de Michoacán, 2015, 2 vols.

Iturbide, Agustín de, Manifiesto al mundo o apuntes para la historia, prólolgo y notas de Laura B. Suárez de la Torre, México, Fideicomiso Teixidor/Libros del Umbral, 2001.

Lemoine Villicaña, Ernesto, "Zitácuaro, Chilpancingo y Apatzingán: tres grandes momentos de la insurgencia mexicana", Boletín del Archivo General de la Nación, segunda serie/IV/3 (México, 1963): 385-710. 
Lemoine Villicaña, Ernesto, Morelos. Su vida revolucionaria a través de sus escritos $y$ de otros testimonios de la época, México, UNAM, 1965.

Lemoine Villicaña, Ernesto, Documentos del Congreso de Chilpancingo, hallados entre los papeles del caudillo José María Morelos, sorprendido por los realistas en la acción de Tlacotepec el 24 de febrero de 1814, estudio histórico y paleografía preparados por..., México, Secretaría de Gobernación, Archivo General de la Nación, Estado de Guerrero/Comisión Especial del Bicentenario del Primer Congreso de Anáhuac, 2013.

Lemoine Villicaña, Ernesto, La última expedición de Morelos, con textos introductorios de Carlos Lozano de la Torre, Ignacio González-Polo y Acosta, Adrián Gerardo Rodríguez y María José Villaseñor, México, Secretaría de Gobernación, Archivo General de la Nación, Estado de Aguascalientes, 2014.

Mina Larrea, Xavier, Proclamas y otros escritos, prólogo de Alberto Gil Novales, edición de Manuel Ortuño Martínez, España, Trama, 2012. Colección Barlovento.

Montejano y Aguiñaga, Rafael, Documentos para la historia de la Guerra de Independencia en San Luis Potosí, San Luis Potosí, Academia de Historia Potosina, 1981. Biblioteca de Historia Potosina, Serie Documentos, 6.

Ocampo, Javier, Las ideas de un día. El pueblo mexicano ante la consumación de su independencia, México, CONACULTA, 2012, $2^{\text {a }}$ ed. Colección Historia.

Ortiz Escamilla, Juan, Guerra y gobierno. Los pueblos y la independencia de México 1808-1825, México, El Colegio de México, Instituto de Investigaciones Dr. José María Luis Mora, 2014, 2a edición corregida y aumentada.

Ortiz Escamilla, Juan, El teatro de la guerra. Veracruz, 1750-1825, Castellón, Universitat Jaume I, 2008. Col.lecció Amèrica, 14.

Ortuño Martínez, Manuel, Xavier Mina. Fronteras de libertad, prólogo de Fernando Serrano Migallón, México, Porrúa, 2003. Colección Sepan Cuantos, 740.

Rayón, Ignacio, Apuntes para la biografía del Exmo. Sr. Lic. D. Ignacio López Rayón, General de División y Benemérito de la Patria, México, Imprenta de Andrade y Escalante, 1856.

Reglamento de divisas para los generales jefes subalternos del Ejército Imperial Mejicano, Mexico, Imprenta de Mariano de Zúñiga y Ontiveros, 1821.

Rivas de la Chica, Adriana Fernanda, Ignacio Allende: una biografía, México, UNAM, Instituto de Investigaciones Históricas, 2013. Serie Historia Moderna y Contemporánea, 62 .

Rivera y San Román, Agustín, Viaje a las ruinas del fuerte del Sombrero, presentación de Sergio López Mena, México, CONACULTA, 2010. Colección Summa Mexicana. 
Rocafuerte, Vicente, Bosquejo ligerísimo de la revolución de Mégico, desde El Grito de Iguala hasta la proclamación imperial de Iturbide, su autor..., un verdadero patriota, prólogo de Horacio Labastida, México, Luz María y Miguel Ángel Porrúa, 1984. [Edición facsimilar de la publicada en Filadelfia en 1822].

Rodríguez Tapia, Andrea, Las ideas políticas de José María Morelos en la historiografía mexicana del siglo XIX, México, Archivo General de la Nación, 2013.

Villaseñor y Villaseñor, Alejandro, Biografías de los héroes y caudillos de la independencia, México, Jus, 1963, 2 tomos. Colección México Heroico.

Zerecero, Anastasio, Memorias para la historia de las revoluciones en México, México, UNAM, 1975. Colección Nueva Biblioteca Mexicana.

Fecha de recepción: 14 de octubre de 2016.

Fecha de envío de las modificaciones: 7 de enero de 2017.

Fecha de aceptación: 9 de enero de 2017.

\section{Generalissimo: configuration, political practices and representations of supreme power (Mexico, 1810-1822)}

This article seeks to analyse the political logic of using the term "Generalissimo" in Mexico during the emancipation process. It studies the military trajectory, the circumstances in which people accessed this position and the activities conducted by these army leaders between 1810 and 1821. The topic is appealing and enlightening, because it allows us not only to understand how the figure of caudillo or leader began to take shape in Mexico, but also how supreme power was exerted in the nineteenth century. The information comes mainly from archives and libraries in Mexico and Spain, as well as from specialized bibliography on Mexican Independence.

KEY WORDS: Generalissimo; political practices; supreme power; war and independence; Mexico. 